\title{
Ishak Score 3-4
}

National Cancer Institute

\section{Source}

National Cancer Institute. Ishak Score 3-4. NCI Thesaurus. Code C157161.

Fibrosis extends beyond the portal areas and bridging fibrosis is present. 